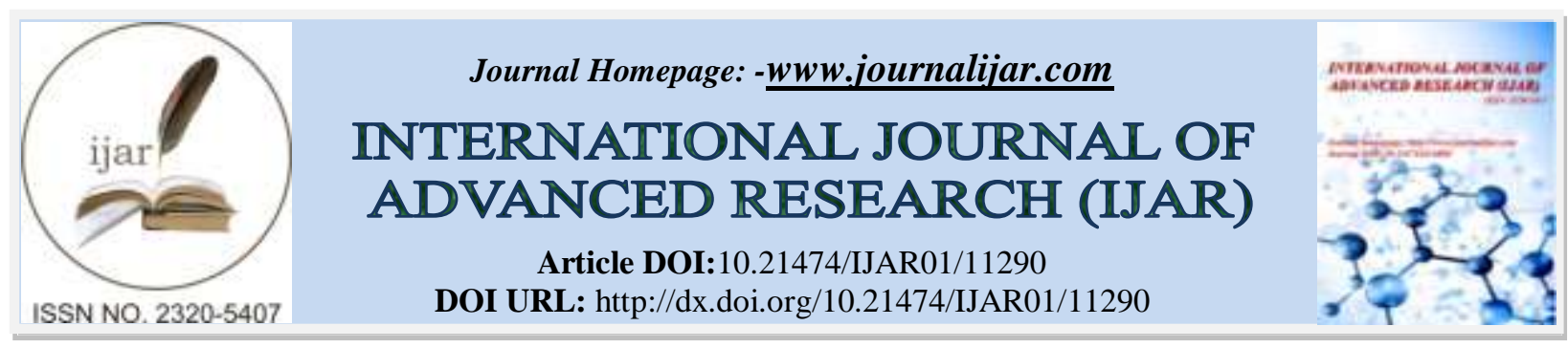

RESEARCH ARTICLE

\title{
COMPARATIVE STUDY OF FINE NEEDLE ASPIRATION AND CELL BLOCK TECHNIQUE IN SALIVARY GLAND LESIONS
}

\author{
Dr. Jasleenkaur Oberoi ${ }^{1}$, Dr. Pradeep Umap ${ }^{2}$, Dr. Suwarna Patil ${ }^{3}$ and Dr. Shobhana Agrawal ${ }^{1}$ \\ 1. Junior Resident III, Department of Pathology, GMC Akola, Maharashtra, India. \\ 2. Professor and Head, Department of Pathology, GMC Akola, Maharashtra, India. \\ 3. Associate Professor, Department of Pathology, GMC Akola, Maharashtra, India.
}

\section{Manuscript Info}

Manuscript History

Received: 05 May 2020

Final Accepted: 10 June 2020

Published: July 2020

Key words:-

Salivary, Cell Block, Fine Needle Aspiration, Histopathology, Lesions

\begin{abstract}
Salivary gland lesions are relatively uncommon in head and neck region. Neoplasms of salivary glands are rare and have diverse histomorphological features in individual lesions and complex classifications. Differentiation of benign from malignant tumours makes these neoplasms diagnostically challenging. Fine needle aspiration cytology (FNAC) is a widely accepted diagnostic tool, due to the superficial location and easy accessibility of salivary glands. The Cell block(CB) technique is simple, reproducible and safe which retrieves small tissue fragments that are processed to form a paraffin block. Hence, the present study was undertaken to emphasize the role of combined approach of FNAC and $\mathrm{CB}$ technique in diagnosing salivary gland lesions. FNAC of 104 cases was done with CB's prepared from 99 cases and histopathological correlation was done in 34 cases. The sensitivity of FNAC and CB was $77.77 \%$ and $88.88 \%$ respectively while the combined sensitivity of FNAC and $\mathrm{CB}$ together increased to $100 \%$. Thus, the combined use of both the techniques increases the diagnostic accuracy and helps the clinician in appropriate management of the patient.
\end{abstract}

Copy Right, IJAR, 2020,. All rights reserved.

\section{Introduction:-}

Salivary gland tumours account for about $3-10 \%$ of head and neck neoplasms ${ }^{(1)}$. The salivary gland system includes major and minor salivary glands. Parotid, submandibular and sublingual are the major salivary glands while minor salivary glands are present in the mucosal lining of the upper aero-digestive tract ${ }^{(2)}$. They are sites of origin of various non-neoplastic and neoplastic lesions. The non-neoplastic lesions include sialadenitis, sialadenosis and cysts. Neoplastic lesions can be either benign or malignant.

Ninty percent of these neoplasms originate from major salivary glands ${ }^{(3)}$. Salivary gland tumours affect the parotid gland in $70 \%$, submandibular gland in 5-10\%, sublingual gland in $1 \%$ and minor glands in $5-15 \%$ of cases ${ }^{(4)}$. Palate is the most frequent site of minor salivary gland tumours ${ }^{(5)}$. However, there are no reliable criteria to differentiate on clinical grounds the benign lesions from malignant lesions and morphologic evaluation is necessary. Neoplasms of the salivary glands are of particular interest to Histopathologists because of their varied histological and biological characteristics ${ }^{(6)}$. 
Fine needle aspiration cytology (FNAC) is the most widely accepted diagnostic tool for salivary gland lesions, due to their superficial location and easy accessibility ${ }^{(7)}$. FNAC is simple, rapid, minimally invasive and reliable. FNAC has high sensitivity, specificity and accuracy ${ }^{(8)}$. Hence, the management can be planned earlier, either conservative treatment for non-neoplastic lesions or radical surgery for malignant tumours ${ }^{(9)}$. Despite the benefits, the mediocre to poor performance of FNAC in salivary gland lesions is well documented. The salivary glands are generally not subjected to incisional or core needle biopsy, due to possible risk factors like fistula formation, tumour spread, damage to the facial nerve and recurrence following capsular disruption ${ }^{(10)}$. However, there is no evidence that either of these complications occur with FNAC.

The CB technique is simple, reproducible and safe. It retrieves small tissue fragments from a FNA specimen which are processed to form a paraffin block. CBs can be prepared from virtually all varieties of cytological samples. CBs augment the utility of cytological samples in analyzing the molecular alterations as effectively as surgical biopsies or resection specimens ${ }^{(11)}$. It increases the cellular yield, gives better architectural patterns and morphological features and thereby increases the efficacy and improves diagnostic accuracy of cytodiagnosis ${ }^{(12)}$. The effectiveness of $\mathrm{CB}$ lies in the availability of diagnostic material for further histological examination, histochemistry and IHC studies for better classification of the tumours ${ }^{(13)}$. It has gained importance because of its pivotal role in diagnosis and ancillary studies.

\section{Materials and Methods:-}

Present study was a cross sectional prospective study done over a period of two years (Nov 17 - Oct 19) in the Department of Pathology, Government Medical College, Akola. It included patients of all ages and either gender having salivary gland lesions referred by surgical departments and willing to take part in study after taking informed consent. Patients not willing to take part in the study and those who had coagulation disorders were excluded.

During the study period, 104 cases underwent FNAC. Of these, CBs were prepared from 99 cases and compared with cytology. Out of 104 cases, histopathology was available for 34 cases.

FNAC was performed by routine procedure and slides stained with Haematoxyline and Eosin (H \& E), May Grunwald Giemsa (MGG) and Papanicolaou (PAP) stains. A separate prick was given for cell block. Material was aspirated with normal saline, emptied in a test tube, centrifuged at 3000 revolution per minute for 10 mins and the supernatant fluid was discarded. To the sediment, an equal amount of citrated plasma and thromboplastin were added and gently tapped and then allowed to stand for 10-15 mins. The cell ball formed was processed as histopathological specimen. Special stains were used wherever required. Histopathology was taken as gold standard to calculate statistical indices.

\section{Results:-}

In the present study, age of patients ranged from 8-85 years. Maximum number of patients were in the age group of $31-40$ yrs (17.3\%). A male predilection was seen with M:F ratio of 1.4:1. All patients (100\%) presented with swelling in the salivary gland regions and association of pain was found in 12 cases $(11.53 \%)$. Out of the 104 cases, 5 patients refused to take part in the study. Thus, from the 99 cases, 82 cases $(82.82 \%)$ were adequate on both FNAC and CBs. While in 5 cases $(5.05 \%)$ only CBs were adequate and in 2 cases $(2.02 \%)$ only FNAC smears were adequate. In 10 cases $(10.10 \%)$ both FNAC smears and CBs were inadequate.

Comparision of adequacy of FNAC, CBs and both together is shown in Table 1

Table 1:- Adequacy of FNAC, CB and combined FNAC and CB in 99 cases.

\begin{tabular}{|c|c|c|}
\hline TECHNIQUE & $\begin{array}{c}\text { NUMBER OF CASES } \\
\text { ADEQUATE }\end{array}$ & PERCENTAGE OF ADEQUACY \\
\hline FNAC & 84 & $\mathbf{8 4 . 8 4 \%}$ \\
\hline Cell block & 87 & $\mathbf{8 7 . 8 7 \%}$ \\
\hline FNAC + Cell block & 89 & $\mathbf{8 9 . 8 9 \%}$ \\
\hline
\end{tabular}

Eighty two cases were adequate on both FNAC and CBs out of which diagnosis correlated in 73 cases $(89.02 \%)$ and in 9 cases $(10.97 \%)$ diagnosis was discordant. In the discordant cases, 3 cases diagnosed as retention cyst on FNAC were diagnosed as chronic sialadenitis, pleomorphic adenoma and Warthin tumour each on CB. One case each of chronic sialadenitis and sialadenosis were diagnosed as Warthin tumour and acinic cell carcinoma on CB 
respectively. One case of pleomorphic adenoma was diagnosed as mucoepidermoid carcinoma on CB. Two cases diagnosed as mucoepidermoid carcinoma were diagnosed as 1 case each of retention cyst and adenoid cystic carcinoma on CB. One case of adenoid cystic carcinoma on FNAC was diagnosed as pleomorphic adenoma on CB.

Out of 104 cases, histopathology samples were received for 34 cases. Diagnosis of FNAC and CBs was compared with the gold standard histopatholgy. Of these, $9(26.47 \%)$ cases were non-neoplastic and $25(73.52 \%)$ cases were neoplastic. Benign neoplasms constituted 16 (64\%) cases and malignant neoplasms constituted $9(36 \%)$ cases. The non-neoplastic cysts included 1 case of mucocoele, 2 cases of retention cyst and 2 cases of lymphoepithelial cyst. Inflammatory conditions included 4 cases $(44.44 \%)$ of chronic sialadenitis. The benign neoplasms included 11 $(68.75 \%)$ cases of pleomorphic adenoma, $3(18.75 \%)$ cases of Warthin tumour and $2(12.5 \%)$ cases of basal cell adenoma. The malignant neoplasms included $4(44.44 \%)$ cases of mucoepidermoid carcinoma, 2 cases of adenoid cystic carcinoma $(22.22 \%)$ and acinic cell carcinoma $(22.22 \%)$ each and $1(11.11 \%)$ case of carcinoma expleomorphic adenoma. There were $6(19.35 \%)$ cases with discordant diagnosis on FNAC, CB and histopathology (Table 2).

Table 2:- Distribution of cases with discordant diagnosis on FNAC, CB and Histopathology.

\begin{tabular}{|c|c|c|c|}
\hline $\begin{array}{c}\text { DIAGNOSIS ON } \\
\text { FNAC }\end{array}$ & $\begin{array}{c}\text { DIAGNOSIS ON CELL } \\
\text { BLOCK }\end{array}$ & $\begin{array}{c}\text { DIAGNOSIS ON } \\
\text { HISTOPATHOLOGY }\end{array}$ & $\begin{array}{c}\text { NUMBER OF } \\
\text { CASES }\end{array}$ \\
\hline Retention cyst & Chronic sialadenitis & Chronic sialadenitis & 1 \\
\hline Sialadenosis & Acinic cell carcinoma & Acinic cell carcinoma & 1 \\
\hline Pleomorphic adenoma & Mucoepidermoid carcinoma & Mucoepidermoid carcinoma & 1 \\
\hline \multirow{2}{*}{$\begin{array}{l}\text { Mucoepidermoid } \\
\text { carcinoma }\end{array}$} & Retention cyst & Mucoepidermoid carcinoma & 1 \\
\hline & Adenoid cystic carcinoma & Adenoid cystic carcinoma & 1 \\
\hline $\begin{array}{l}\text { Adenoid cystic } \\
\text { carcinoma }\end{array}$ & Pleomorphic adenoma & Pleomorphic adenoma & 1 \\
\hline \multicolumn{3}{|c|}{ TOTAL } & 6 \\
\hline
\end{tabular}

In the present study, sensitivity, specificity and accuracy of FNAC was $77.77 \%, 95.65 \%$ and $90.62 \%$ respectively. The sensitivity, specificity and accuracy of CBs were $88.88 \%, 100 \%$ and $96.96 \%$ respectively and when the two techniques were combined, the indices increased to $100 \%$. 
Figure 1:- Microphotographs of different lesions on CB in salivary glands (H \& E, 400X).

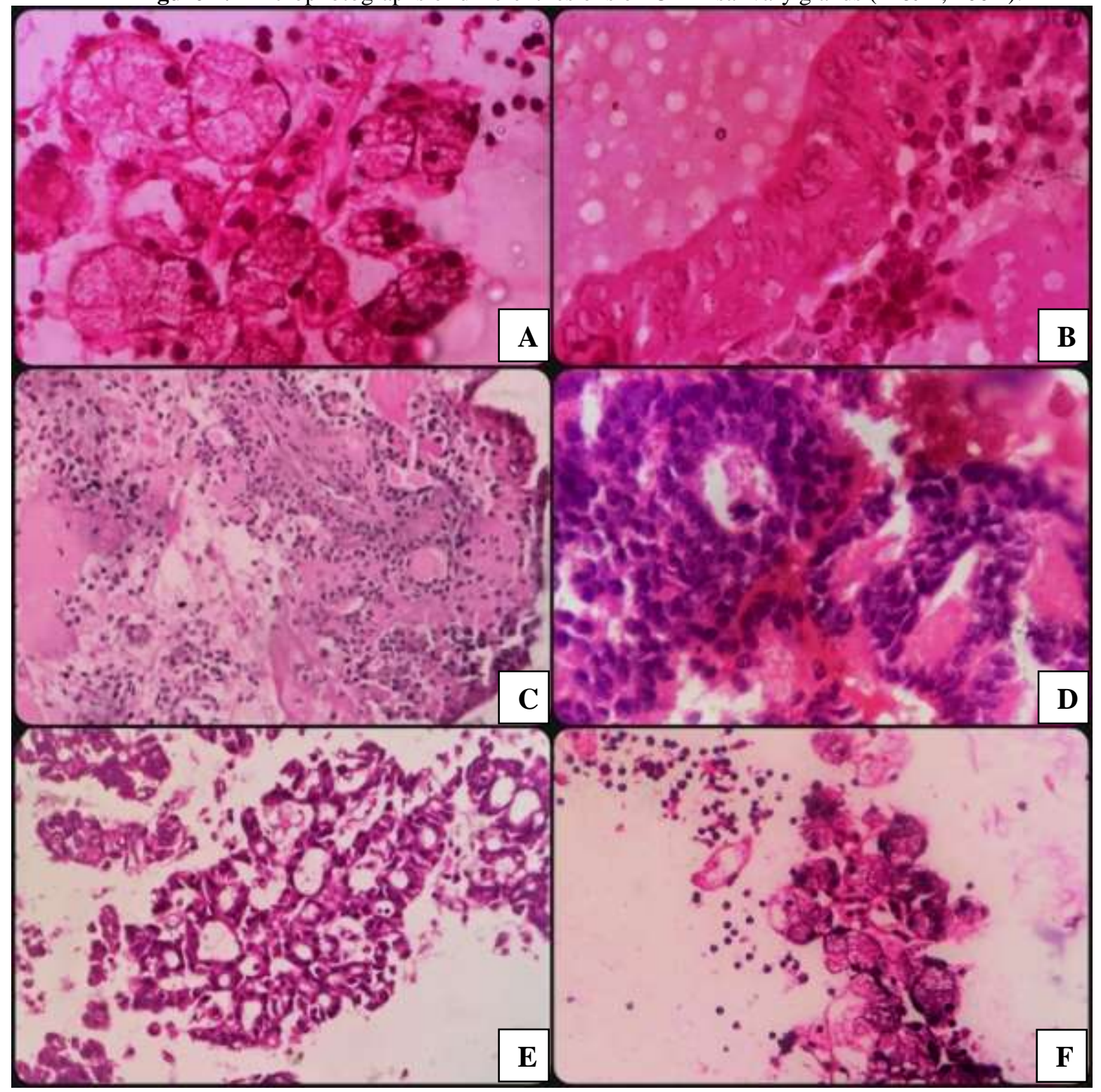

A: Sialadenosis, B: Warthins tumour, C: Pleomorphic adenoma, D: Basal cell adenoma, E: Adenoid cystic carcinoma, F: Chronic sialadenitis

\section{Discussion:-}

FNAC is widely accepted as a diagnostic method that can be obtained without anesthesia or sedation, with minimal risk to patients. Definitive diagnosis is possible in many lesions but when a specific diagnosis cannot be rendered, the information provided by cytology (e.g., inflammation vs neoplasia) is useful for choosing additional tests to make a definitive diagnosis. It is sometimes very difficult to identify the tissue of origin on FNAC. Histology provides a definitive diagnosis and since biopsies preserve tissue architecture, grading and classification of the tumour is usually possible. The cell block (CB) technique refers to processing of sediments, blood clots or grossly visible tissue fragments from cytological specimens into paraffin blocks that can be cut and stained by the same methods used for histopathology. Thus, CB technique helps to bridge this gap between cytology and histopathology. This technique brings additional tissue architectural information and can be used for ancillary tests such as immunocytochemistry and molecular techniques. Preserving cytological material for future use is an advantage of $\mathrm{CB}$ in the era of targeted therapy and biobanking. The $\mathrm{CB}$ is thus central to the future of cytology: More can be done with less material and with less invasiveness to the patients ${ }^{(14)}$. 
In this study, the age range of 8 - 85 years was comparable to $9-85$ years as studied by Koirala et al. ${ }^{(15)}$. The M : F ratio was 1.4:1. There was a slight male predominance in the present study. The results of previous studies regarding sex distribution of salivary glands swellings were variable. Some of the studies showed a female preponderance, whereas others showed slight excess in males, but sex difference has not been statistically significant. The site, age and sex distributions of different types of salivary gland neoplasms vary with race and geographic location ${ }^{(16)}$. Predominant clinical features of swelling and pain were comparable to studies done by Madhu et al. ${ }^{(16)}$ and Shetty et al. ${ }^{(10)}$. Percentage adequacy of FNAC, CB and combined FNAC and CB were $84.84 \%, 87.87 \%$ and $89.89 \%$ respectively. As CB studies particularly of salivary gland lesions are very few the adequacy of combined FNAC and $\mathrm{CB}$ were compared to studies done in various other organs. Parate et $\mathrm{al}^{(17)}$ showed that combined adequacy of FNAC and $\mathrm{CB}(94.44 \%)$ was more than $\mathrm{FNAC}(90 \%)$ or $\mathrm{CB}(86.94 \%)$ alone. The adequacy of $\mathrm{CB}$ was less than that of FNAC due to paucity of material in needle hub after making smear. In this study, a second pass was given to obtain material for CB preparation which increased the adequacy. The inadequate cases were mainly due to haemorrhagic aspirate obtained after prior prick and in some cystic lesions which showed scanty cellularity. Thus, repeat aspiration or fresh pass can be used to obtain adequate material for $\mathrm{CB}$ which would increase the diagnostic accuracy. According to studies done by Pal et al. ${ }^{(18)}$ and Pawar et al. ${ }^{(19)}$ cell block gives better architectural patterns and morphological features which was also true in the present study.

Histopathological correlation was possible for 34 cases. Out of these, 9 (26.47\%) cases were non-neoplastic and 25 (73.52\%) cases were neoplastic. Chronic sialadenitis was the most common non-neoplastic lesion. The most common benign neoplasm was pleomorphic adenoma followed by Warthin tumour. Mucoepidermoid carcinoma was the most common malignancy.Six (19.35\%) cases had a discordant diagnosis. One case diagnosed as retention cyst on FNAC was correctly diagnosed as chronic sialadenitis on CB. Thus, CB gave a more specific diagnosis. One case of sialadenosis on FNAC was a false negative case for FNAC. It was diagnosed as acinic cell carcinoma on CB and histopathology. Thus, CB helped in identifying a malignant lesion. One case of mucoepidermoid carcinoma was misdiagnosed as retention cyst on CB. This was a false negative case for CB. FNAC diagnosis of mucoepidermoid carcinoma was confirmed by histopathology. Here FNAC correctly picked up the diagnosis while CB couldn't. One case of adenoid cystic carcinoma was misdiagnosed as mucoepidermoid carcinoma on FNAC but picked up by CB. In this case, FNAC correctly identified the case as malignant but specific diagnosis was provided by $\mathrm{CB}$ which gives the architectural pattern that helps in specific diagnosis of lesion. One case of pleomorphic adenoma was misdiagnosed as adenoid cystic carcinoma on FNAC but correctly diagnosed on CB. This was false positive case for FNAC. It is due to the varied histological pattern of various salivary gland lesions and different architectural patterns even within a same lesion. Another case of mucoepidermoid carcinoma on CB and histopathology was diagnosed as pleomorphic adenoma on FNAC. This was a false negative case for FNAC but the case was rightly diagnosed on CB. Thus, in this study, the sensitivity, specificity and diagnostic accuracy of FNAC in differentiating benign versus malignant conditions were $77.77 \%, 95.65 \%$ and $90.62 \%$ respectively which were comparable to statistical analysis of Vaidya et al. ${ }^{(1)}$ and Fernandes et al. ${ }^{(20)}$. When FNAC and CB were used together there were no false positive and false negative cases thus increasing the statistical indices to $100 \%$. Study done by Basnet et al. ${ }^{(21)}$ found that with the combined use of smear and cell block, the diagnostic accuracy of the tumours approaches 100\% and also significantly improves diagnostic and sub typing accuracy of malignancies.

\section{Conclusion:-}

Cell block allows the recovery \& processing of minute amount of cellular material which in today's world can be used for various immunohistochemical and molecular diagnostic studies. When used in conjunction with FNAC, Cell block increases sensitivity of cytodiagnosis. It bridges the gap between cytology and histopathology. Cell block is a complimentary technique which can be used as adjuvant to cytology but cannot replace it.

\section{References:-}

1. Vaidya S, Sinha A, Narayan S, Adhikari S, Sabira K. A comparative study of fine-needle aspiration cytology and histopathology in salivary gland lesions. J Pathol Nepal. 2011;1:108-13.

2. Kattimani SR, Patil RS, Anita AM, Patil AG, Neeha S. Aspiration Cytology of Salivary Gland Lesions - A 5 year study. Glob J Res Anal. 2017;6(4):15-8.

3. Rai S, Sandhu S, Sodhi SPS. Pleomorphic adenoma of submandibular gland: An uncommon occurrence. Natl J Maxillofac Surg. 2011;2(1):66.

4. Patil P, Burde K, Naikmasur VG, Thorawat A. Pleomorphic adenoma of submandibular gland: A case report with review of literature. Dent Res J (Isfahan). 2014;11(3):411-4. 
5. Rawson K, Kallali B, George A, Nair A. Minor Salivary Gland Neoplasms of Palate: Case Series with Differential Diagnosis and Review of Literature. J Indian Acad Oral Med Radiol. 2017;29(4):321.

6. Laishram R, Kumar Ka, Pukhrambam G, Laishram S, Debnath K. Pattern of salivary gland tumors in Manipur, India: A 10 year study. South Asian J Cancer. 2013;2(4):250.

7. Jain R, Gupta R, Kudesia M, Singh S. Fine needle aspiration cytology in diagnosis of salivary gland lesions: A study with histologic comparison. Cytojournal. 2013 Jan 1;10(1).

8. Singh A, Haritwal A, Murali BM. Correlation between cytology and histopathology of the salivary gland. Australas Med J. 2011;4(2):66-71.

9. Parmar MD, Suri SK, Ghoghari D V. Role of fine needle aspiration cytology in salivary glands lesions. J Res Med Dent Sci|. 2014;2(3):23-7.

10. Shetty A, Geethamani V. Role of fine-needle aspiration cytology in the diagnosis of major salivary gland tumors: A study with histological and clinical correlation. J Oral Maxillofac Pathol. 2016 May 1;20(2):224-9.

11. Jain D, Mathur SR, Iyer VK. Cell blocks in cytopathology: A review of preparative methods, utility in diagnosis and role in ancillary studies. Vol. 25, Cytopathology. Blackwell Publishing Ltd; 2014. p. 356-71.

12. Khan S, Omar T, Michelow P. Effectiveness of the cell block technique in diagnostic cytopathology. J Cytol. 2012 Jul;29(3):177-82.

13. Bandyopadhyay A, Bhattacharyya S, Roy S, Majumdar K, Bose K, Boler A. Cytology microarray on cell block preparation: A novel diagnostic approach in fluid cytology. J Cytol. 2019 Apr 1;36(2):79-83.

14. Krogerus L, Kholová I. Cell Block in Cytological Diagnostics: Review of Preparatory Techniques. Acta Cytol. 2018;62(4):237-43.

15. Koirala S, Sayami G, Pant A. Correlation of FNAC and histopathology in diagnosis of salivary gland lesions. J Pathol Nepal. 2014;4(8):654-7.

16. Madhu B, Das V. Clinico-Pathological Study \& Management of Parotid Gland Tumors. IOSR J Dent Med Sci. 2015;14(4):48-54.

17. Parate SN, Pawar PS, Kakade A. Role of Cell Block Preparation in Cytopathological Diagnosis. Int J Contemp Med Res. 2019;6(7):G26-31.

18. Pal S, Murmu D, Goswami BK. Ascitic fluid cytology in suspected malignant effusions with special emphasis on cell block preparation. J Evol Med Dent Sci. 2015 Jul 24;4(60):10488-93.

19. Pawar S, Sameer M, Ahuja M, Patil A. Sensitivity and Specificity of Cell Block Method in Diagnosis of Lung Malignancies. IOSR J Dent Med Sci. 2016;15(4):86-99.

20. Fernandes H, D'Souza CRS, Khosla C, George L, Katte NH. Role of FNAC in the preoperative diagnosis of salivary gland lesions. J Clin Diagnostic Res. 2014;8(9):1-3.

21. Basnet S, Talwar O. Role of cell block preparation in neoplastic lesions. J Pathol Nepal. 2012;2(4):272-6. 